\title{
Resveratrol induces apoptosis MH7A human rheumatoid arthritis synovial cells in a sirtuin 1-dependent manner
}

\author{
Hiroshi Nakayama $\cdot$ Takahiro Yaguchi • \\ Shinichi Yoshiya $\cdot$ Tomoyuki Nishizaki
}

Received: 23 March 2010/Accepted: 28 July 2010/Published online: 10 August 2010

(C) The Author(s) 2010. This article is published with open access at Springerlink.com

\begin{abstract}
Resveratrol, a phytoalexin, reduced the viability of MH7A cells, a human rheumatoid arthritis synovial cell line. In the apoptosis assay, resveratrol increased TUNEL-positive cells and stimulated H2A.X phosphorylation. Resveratrol disrupted mitochondrial membrane potentials in MH7A cells and stimulated cytochrome c release from the mitochondria to the cytosol. Resveratrol activated caspase- 3 and caspase- 9 but not caspase- 8 in MH7A cells. Resveratrol upregulated the expression of the NAD-dependent deacetylase sirtuin 1 mRNA and downregulated the expression of the $\mathrm{Bcl}-\mathrm{X}_{\mathrm{L}} \mathrm{mRNA}$, and resveratrol-induced $\mathrm{MH} 7 \mathrm{~A}$ cell death, mitochondrial damage, and caspase-3/-9 activation were prevented by sirtinol, an inhibitor of sirtuin 1. The results of the present study show that resveratrol induces MH7A cell apoptosis by activating caspase- 9 and the effector caspase- 3 along mitochondrial disruption as a result of reduced $\mathrm{Bcl}-\mathrm{X}_{\mathrm{L}}$ expression, allowing cytochrome $\mathrm{c}$ release from the mitochondria into the cytosol, in a sirtuin 1-dependent manner. This suggests that resveratrol could suppress hyperplasia of synovial cells, a critical factor of rheumatoid arthritis.
\end{abstract}

Keywords Resveratrol - MH7A human synovial cell · Apoptosis · Sirtuin 1 Rheumatoid arthritis

H. Nakayama $\cdot$ T. Yaguchi $\cdot$ S. Yoshiya $\cdot$ T. Nishizaki $(\square)$ Division of Bioinformation, Department of Physiology, Hyogo College of Medicine, Nishinomiya 663-8501, Japan e-mail: tomoyuki@hyo-med.ac.jp

H. Nakayama $\cdot$ S. Yoshiya

Department of Orthopedic Surgery, Hyogo College of Medicine, Nishinomiya, Japan

\section{Introduction}

Rheumatoid arthritis is a systemic autoimmune disease characterized by chronic inflammation of multiple joints, with disruption of joint cartilage. Lines of evidence have pointed to inflammatory cytokines inducing hyperplasia of synovial cells in joints as an etiology for rheumatoid arthritis. Of cytokines, tumor necrosis factor- $\alpha$ (TNF- $\alpha)$ and interleukin-1 (IL-1) have been highlighted, since high concentrations of TNF- $\alpha$ and IL- 1 are found with the synovial fluid and the plasma for patients with rheumatoid arthritis [1, 2] and those cytokines produce matrix metalloproteinases or activate osteoclasts, causing irreversible damage to soft tissues and bones [3]. TNF- $\alpha$ inhibitors, anti-TNF antibodies, a soluble TNF receptor fusion protein, and an IL-1 receptor antagonist have been attempted for treatment of rheumatoid arthritis, but their side effects such as serious infections and inducible malignant tumors remain not to be resolved [4].

Resveratrol, a phytoalexin that is present in grape skin and red wine, exerts a variety of actions to reduce superoxides, suppresses cartinogenesis and angiogenesis, prevent diabetes mellitus, inhibit inflammation, or prolong life span [5]. Furthermore, resveratrol decreases plaque formation relevant to neurodegenerative diseases such as Alzheimer disease and Huntington disease [6]. Of particular interest is that resveratrol is potent and specific inhibitor of NF- $\kappa$ B activation induced by TNF- $\alpha$ or IL- $1 \beta$, and therefore, resveratrol might be available for therapy of rheumatoid arthritis [7-9].

The present study aimed at understanding the mechanism of resveratrol-induced apoptosis in MH7A cells, a human rheumatoid arthritis synovial cell line. We show here that resveratrol induces MH7A cell apoptosis by activating caspase- 9 and the effector caspase- 3 in response 
to mitochondrial damage in a sirtuin 1-dependent manner. This supports the possibility for resveratrol as a beneficial drug for the treatment of rheumatoid arthritis.

\section{Materials and methods}

Cell culture

MH7A cells were obtained from Riken cell bank (Ibaraki, Japan). Cells were cultured in a culture medium; RPMI1,640 (Wako, Osaka, Japan) supplemented with 10\% heatinactivated fetal bovine serum (FBS), penicillin (final concentration, $100 \mathrm{U} / \mathrm{ml}$ ), and streptomycin (final concentration, $0.1 \mathrm{mg} / \mathrm{ml}$ ), in a humidified atmosphere of $5 \% \mathrm{CO}_{2}$ and $95 \%$ air at $37^{\circ} \mathrm{C}$.

\section{Cell viability}

Cell viability was evaluated by the method using 3-(4,5dimethyl-2-thiazolyl)-2,5-diphenyl-2H-tetrazolium bromide (MTT) as previously described [10].

Terminal deoxynucleotidyl transferase-mediated dUTP nick end labeling (TUNEL) assay

MH7A cells were fixed with 4\% paraformaldehyde. After removing inactivate endogenous peroxidase with methanol containing $0.3 \% \mathrm{H}_{2} \mathrm{O}_{2}$, a permeabilization buffer was applied to cells and stood on ice for $5 \mathrm{~min}$. Then, a Labeling Reaction Mixture was added and incubated in a humidified chamber at $37^{\circ} \mathrm{C}$ for $60 \mathrm{~min}$. Reactive cells were stained with $3 \%$ methyl green and detected with a light microscope.

\section{H2A phosphorylation assay}

MH7A cells were incubated in a chemiluminescence detection assay kit (Upstate, Charlottesville, Virginia, USA) and reacted with an anti-phospho-H2A.X (Ser139) followed by an anti-mouse-HRP conjugate. Phosphorylation of H2A.X at Ser139 was stained with a chemiluminescent HRP substrate LumiGLO, and signals were detected with a microplate luminometer (ARVO mx/light, Perkinelmer, Waltham, MA, USA).

Assay of mitochondrial membrane potentials

Mitochondrial membrane potentials were measured using a DePsipher ${ }^{\mathrm{TM}}$ kit as previously described [10]. Briefly, MH7A cells were untreated and treated with resveratrol $(100 \mu \mathrm{M})$ in the absence and presence of sirtinol $(10 \mu \mathrm{M})$ for $24 \mathrm{~h}$. After washing with cold phosphate-buffered saline (PBS), cells were incubated in a DePsipher ${ }^{\mathrm{TM}}$ solution at $37^{\circ} \mathrm{C}$ for $20 \mathrm{~min}$. Then, cells were washed with $1 \mathrm{ml}$ of a reaction buffer containing a stabilizer solution. The fluorescent signals were observed with a laser scanning microscopes (LSM 510, Carl Zeiss Co., Ltd, Germany) equipped with an epifluorescence device using a fluorescein long-pass filter (fluorescein and rhodamine) at an absorbance of $590 \mathrm{~nm}$ for red aggregations and at an absorbance of $530 \mathrm{~nm}$ for green aggregations.

Reverse transcription-polymerase chain reaction (RT-PCR)

Total RNAs of MH7A cells before and after treatment with resveratrol $(100 \mu \mathrm{M})$ were purified by an acid/guanidine/ thiocyanate/chloroform extraction method using a SepasolRNA I Super kit. After purification, total RNAs were treated with RNase-free DNase I (2 unit) at $37^{\circ} \mathrm{C}$ for $30 \mathrm{~min}$ to remove genomic DNAs, and $10 \mu \mathrm{g}$ of RNAs were resuspended in water. Then, oligo dT primers, dNTP, $5 \times$ first-strand buffer, and SuperScript III RNase H-reverse transcriptase were added to the RNA solution and incubated at $65^{\circ} \mathrm{C}$ for $5 \mathrm{~min}$ followed by $60^{\circ} \mathrm{C}$ for $1 \mathrm{~min}, 56^{\circ} \mathrm{C}$ for $60 \mathrm{~min}, 58^{\circ} \mathrm{C}$ for $60 \mathrm{~min}, 85^{\circ} \mathrm{C}$ for $5 \mathrm{~min}$ to synthesize the first strand cDNA. Subsequently, $1 \mu \mathrm{l}$ of the reaction solution was diluted with water and mixed with $10 \times$ PCR reaction buffer, dNTPs, $\mathrm{MgCl}_{2}$, oligonucleotide, dimethylsulfoxide [final concentration, 5\% (v/v)], and 1 unit of Taq polymerase (Fermentas, St. Leon-Roth, Germany) (final volume, $20 \mu \mathrm{l})$. RT-PCR was carried out with a Takara Thermal cycler Dice (Takara Co. Ltd., Shiga, Japan) programmed as follows: the first one step, $94^{\circ} \mathrm{C}$ for $2 \mathrm{~min}$ and the ensuing 30 cycles, $94^{\circ} \mathrm{C}$ for $1 \mathrm{~s}, 62^{\circ} \mathrm{C}$ for $15 \mathrm{~s}$, and $72^{\circ} \mathrm{C}$

Table 1 Primers used for RT-PCR

\begin{tabular}{llll}
\hline Gene name & Sense primer & Anti-sense primer & Base pair \\
\hline Bad & CTGGGGCTGTGGAGATCCGGAGTCGCC & TCACTGGGAGGGGGCGGAGCTTCCCC \\
Bak & GAGCCCATTCCCACCATTCTACCT & AGAGAGGAAGGGAGAGAACTGAGAGGAC & 320 \\
Bax & GGGAGACACCTGAGCTGACC & GGACTCCAGCCACAAAGATGG & 404 \\
Bcl-2 & GAACTGGGGGAGGATTGTGGCC & TCGACGTTTTGCCTGAAGACTGTTAA & 486 \\
Bcl-X & AGGGAGGCAGGCGACGAGTTT & TGAAGAGTGAGCCCAGCAGAACCA & 421 \\
Srituin 1 & ATTACTGAAAAACCTCCACGAACACAAAA & GCCTACTAATCTGCTCCTTTGCCACTCT & 379
\end{tabular}


for 30 s using primers shown in Table 1. PCR products were stained with ethidium bromide and visualized by $2 \%(\mathrm{w} / \mathrm{v})$ agarose electrophoresis.

\section{Western blotting}

After treatment with resveratrol $(100 \mu \mathrm{M})$ for $6-24 \mathrm{~h}$, MH7A cells were harvested and centrifuged at $600 \times g$ for $10 \mathrm{~min}$. After washing out with $1 \mathrm{ml}$ of PBS, the pellet was resuspended in $50 \mu \mathrm{l}$ of a buffer A (20 mM Hepes, $10 \mathrm{mM}$ $\mathrm{KCl}, 1.5 \mathrm{mM} \mathrm{MgCI}_{2}, 1 \mathrm{mM}$ EDTA, $1 \mathrm{mM}$ EGTA, $1 \mathrm{mM}$ dithiothreitol, $0.1 \mathrm{mM}$ phenylmethylsulfonyl fluoride, $250 \mathrm{mM}$ sucrose, $\mathrm{pH} 7.5$ ) and homogenized. The lysate was centrifuged at $1,000 \times g$ for $10 \mathrm{~min}$, and the supernatant was further centrifuged at $10,000 \times g$ for $1 \mathrm{~h}$. The pellet and supernatant were used as the mitochondria- and cytosol-enriched fraction, respectively. Each fraction was loaded on $12 \%$ sodium dodecyl sulfate polyacrylamide gel electrophoresis (SDS-PAGE) and transferred to polyvinylidene difluoride membranes. Blotting membranes were blocked with TTBS (150 mM NaCl, $0.05 \%$ Tween 20 , and $20 \mathrm{mM}$ Tris, $\mathrm{pH}$ 7.5) containing 5\% BSA and subsequently reacted with an anti-cytochrome c antibody (1:400) (Chemicon, Billerica, MA, USA), followed by an HRPconjugated goat anti-mouse IgG antibody. Immunoreactivity was detected with an ECL kit (GE Healthcare, NJ, USA) and visualized using a chemiluminescence detection system (FUJIFILM, Tokyo, Japan). Signal density was measured with an Image Gauge software (FUJIFILM, Tokyo, Japan).

\section{Enzymatic assay of caspase activity}

Caspase activation was measured using a caspase fluorometric assay kit (Ac-Asp-Glu-Val-Asp-MCA for a caspase3 substrate peptide; Ac-Ile-Glu-Thr-Asp-MCA for a caspase-8 substrate peptide; and Ac-Leu-Glu-His-Asp-MCA for a caspase-9 substrate peptide) as previously described [10].

\section{Results}

Resveratrol induces apoptosis MH7A cells

In the MTT assay, resveratrol reduced MH7A cell viability in a concentration (1-200 $\mu \mathrm{M})$ - and treatment time (24-72 h)dependent manner (Fig. 1a), suggesting that resveratrol induces MH7A cell death. To examine whether it is due to apoptotic cell death, we carried out TUNEL assay and H2A phosphorylation assay. Resveratrol increased TUNELpositive cells in a concentration (100-200 $\mu \mathrm{M})$-dependent
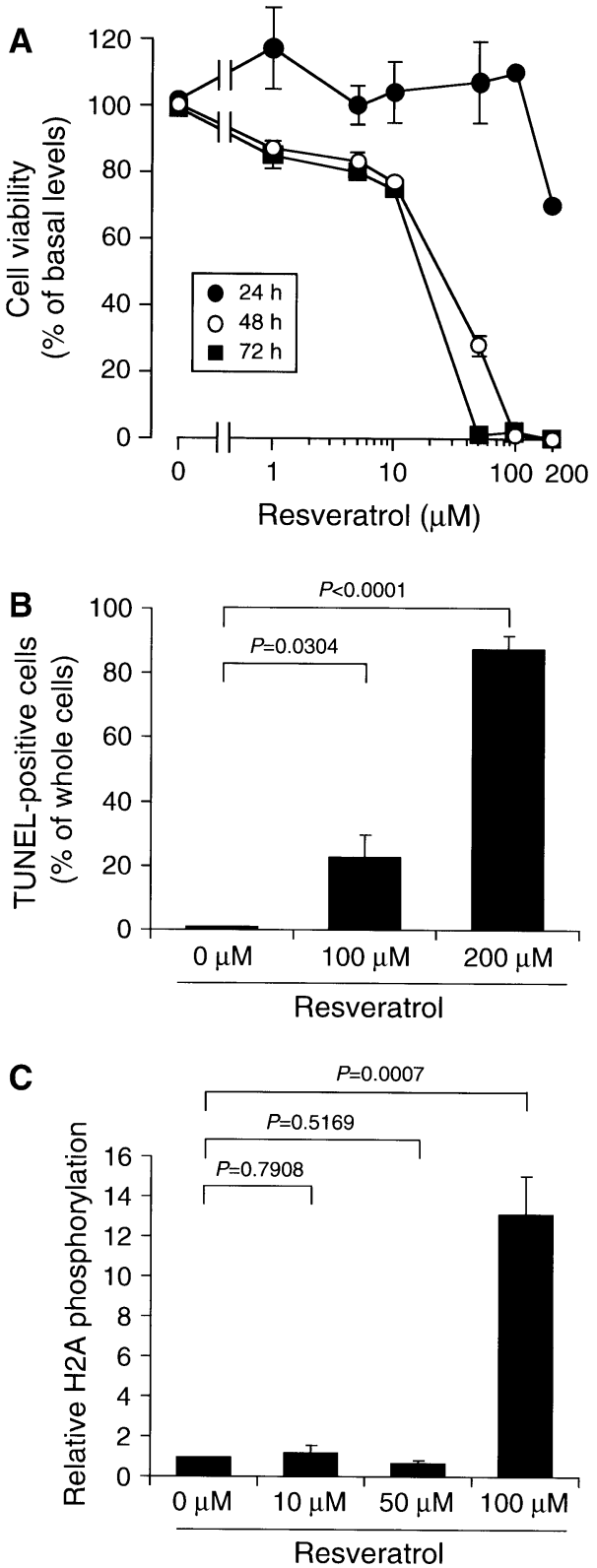

Fig. 1 Resveratrol induces apoptosis in MH7A cells. a MH7A cells were treated with resveratrol at concentrations as indicated for 24-72 $\mathrm{h}$ in serum-free culture medium, and cell viability was quantified with an MTT assay. In the graph, each point represents the mean $( \pm$ SEM $)$ percentage of basal levels (MTT intensities for cells untreated with resveratrol) $(n=8)$. b Cells were treated with resveratrol at concentrations as indicated for $24 \mathrm{~h}$ in serum-free culture medium, and TUNEL-positive cells were counted. In the graph, each column represents the mean $( \pm$ SEM) percentage of basal levels (TUNELpositive cell numbers without resveratrol treatment) $(n=3-6)$. $P$ values, unpaired $t$-test. c Cells were treated with resveratrol at concentrations as indicated for $24 \mathrm{~h}$ in FBS-free culture medium, and H2A.X phosphorylation was quantified. In the graph, each column represents the mean $( \pm$ SEM) ratio against basal levels (H2A.X phosphorylation without resveratrol treatment) $(n=4) . P$ values, unpaired $t$-test 
manner (Fig. 1b), indicating that resveratrol induces MH7A cell apoptosis. DNA damage or apoptosis is recognized to stimulate phosphorylation of histone H2A.X. Resveratrol $(100 \mu \mathrm{M})$ significantly enhanced H2A.X phosphorylation, the extent reaching approximately 13 folds of control levels (Fig. 1c). This provides further evidence for resveratrolinduced MH7A cell apoptosis.

Resveratrol disrupts mitochondrial membrane potentials in a sirtuin 1-dependent manner

Resveratrol is shown to regulate mitochondrial functions or calories by interacting with NAD-dependent deacetylase sirtuin $1[11,12]$. Interestingly, resveratrol-induced MH7A cell death was inhibited by sirtinol $(10 \mu \mathrm{M})$, an inhibitor of sirtuin 1 (Fig. 2), suggesting that resveratrol induces MH7A cell death in a sirtuin 1-dependent manner. Moreover, the resveratrol effect was inhibited by trichostatin A $(30 \mathrm{nM})$, and inhibitor of histone deacetylase (HDAC) (Fig. 2). This may account for the implication of sirtuin 1-regulated apoptosis-related gene transcription in the resveratrol effect.

To see whether resveratrol-induced MH7A cell apoptosis is mediated via the mitochondria, mitochondrial membrane potentials were monitored. For untreated cells, orange-red fluorescent signals alone were found (Fig. 3a, b). In contrast, resveratrol $(100 \mu \mathrm{M})$ accumulated green fluorescent signals without orange-red fluorescent signal (Fig. 3c, d), indicating that resveratrol disrupts mitochondrial membrane potentials in MH7A cells. The resveratrol effect on mitochondrial membrane potentials was abolished by sirtinol $(10 \mu \mathrm{M})$

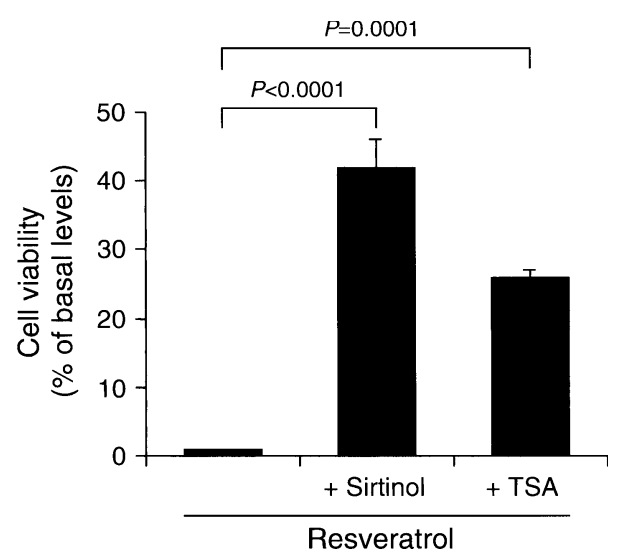

Fig. 2 Resveratrol-induced MH7A cell death is inhibited by a sirtuin 1 inhibitor or an HDAC inhibitor. MH7A cells were treated with resveratrol $(100 \mu \mathrm{M})$ in the absence and presence of sirtinol $(10 \mu \mathrm{M})$ or tricostatin A (TSA) $(30 \mathrm{nM})$ for $24 \mathrm{~h}$ in serum-free culture medium, and cell viability was quantified with an MTT assay. In the graph, each column represents the mean $( \pm \mathrm{SEM})$ percentage of basal levels (MTT intensities for cells untreated with any drug) $(n=4)$. $P$ values, unpaired $t$-test
(Fig. 3e, f). This implies that resveratrol disrupts mitochondrial membrane potentials in MH7A cells under the control of sirtuin 1. Taken together, these results indicate that resveratrol induces $\mathrm{MH} 7 \mathrm{~A}$ cell apoptosis by damaging the mitochondria in a sirtuin 1-dependent manner.

In the RT-PCR analysis, resveratrol $(100 \mu \mathrm{M})$ increased the expression of the sirtuin 1 mRNA in MH7A cells in a treatment time (20-60 min)-dependent manner (Fig. 4a). This points to sirtuin 1 as a significant target in resveratrolinduced MH7A cell death. Accumulating evidence has shown that resveratrol upregulates or downregulates the expression of the Bcl-2 family that includes Bcl-2 and Bcl$\mathrm{X}_{\mathrm{L}}$, to prevent from mitochondrial damage, and Bad, Bax, and Bak, to induce mitochondrial damage [13]. Resveratrol $(100 \mu \mathrm{M})$ downregulated the expression of the $\mathrm{Bcl}-\mathrm{X}_{\mathrm{L}}$ mRNA in MH7A cells from 1-h through 3-h treatment
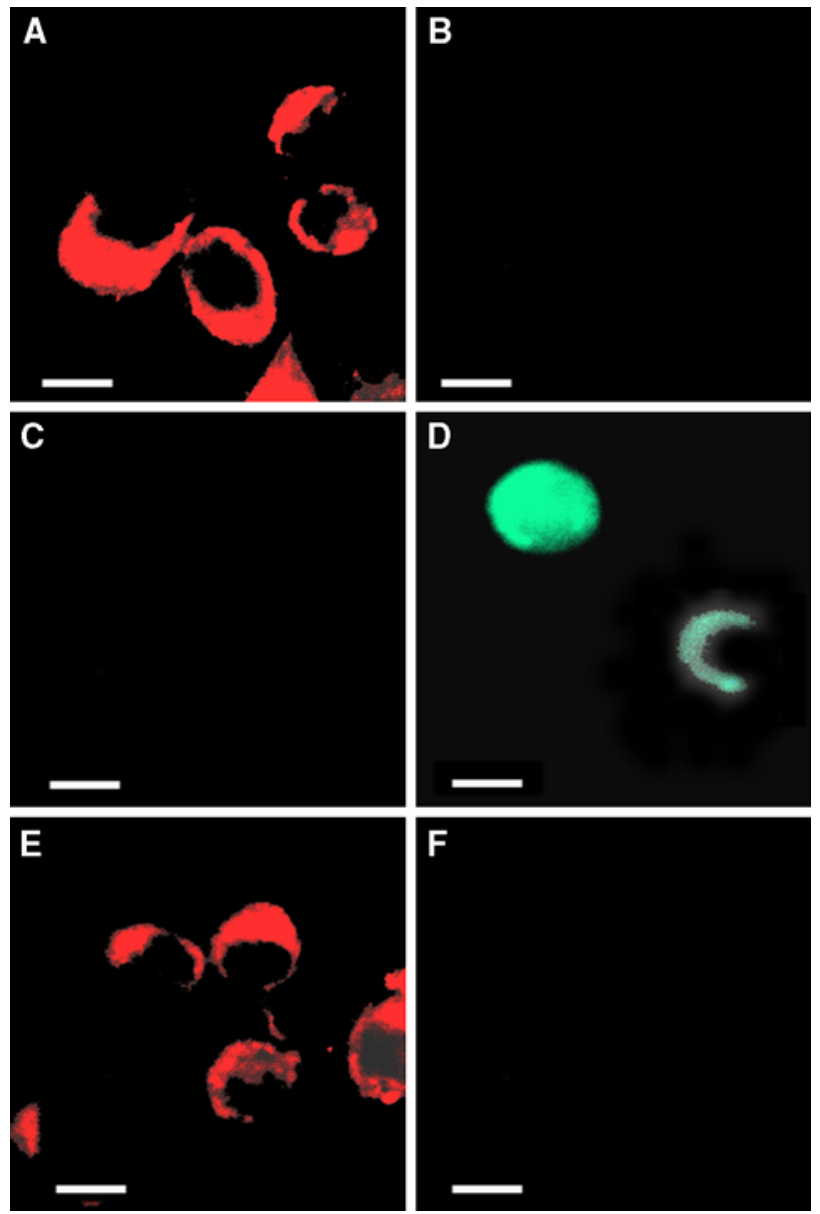

Fig. 3 Resveratrol disrupts mitochondrial membrane potentials in a SIRT1-dependent manner. MH7A cells were treated with resveratrol $(100 \mu \mathrm{M})$ in the absence and presence of sirtinol $(10 \mu \mathrm{M})$ for $24 \mathrm{~h}$ in serum-free culture medium, and mitochondrial membrane potentials were monitored. a, c, e Orange-red fluorescent images at an absorbance of $590 \mathrm{~nm}$. b, d, f Green fluorescent images at an absorbance of $530 \mathrm{~nm}$. Note that similar results were obtained with 3 independent experiments 
Fig. 4 Resveratrol upregulates the expression of the sirtuin 1 mRNA and downregulates the expression of the $\mathrm{Bcl}-\mathrm{X}_{\mathrm{L}}$ mRNA. MH7A cells were untreated (Control) and treated with resveratrol $(100 \mu \mathrm{M})$ for 20-60 min or $0.5-3 \mathrm{~h}$ in serumfree culture medium, and then RT-PCR was carried out. In the graph, each point represents the ratio against the intensity at $0 \mathrm{~min} / \mathrm{h}$ regarding as 1 . Note that similar results were obtained with 3 independent experiments
A

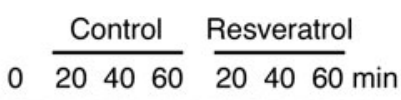

SIRT 1

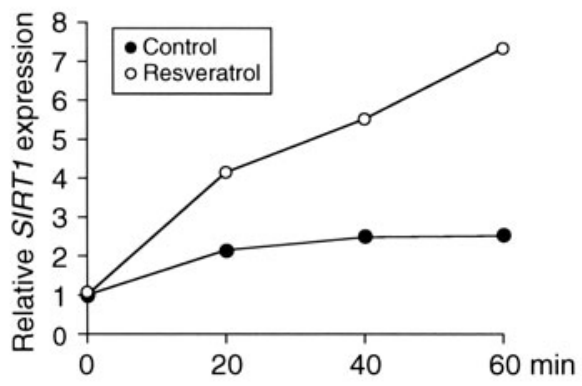

C
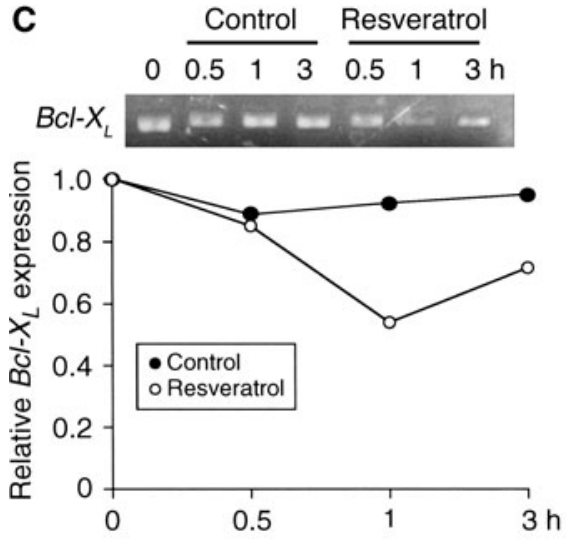

E

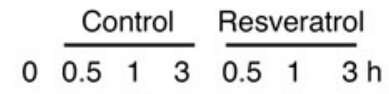

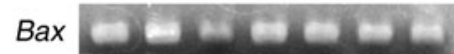

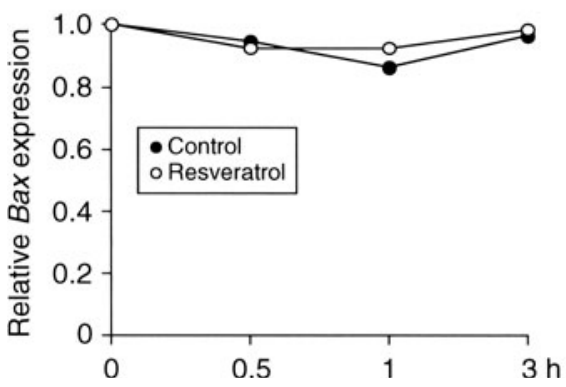

B
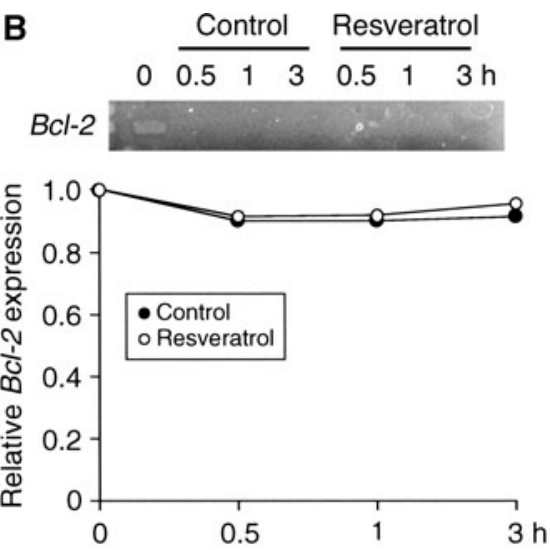

D

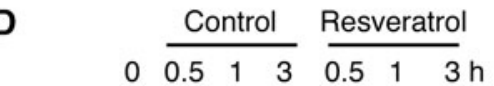

$\mathrm{Bad}$

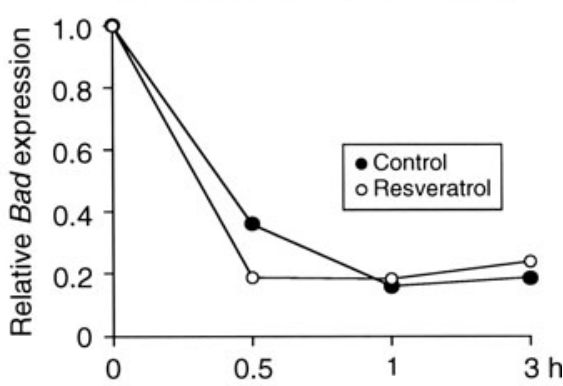

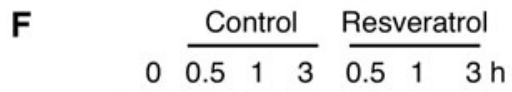

Bak $=$

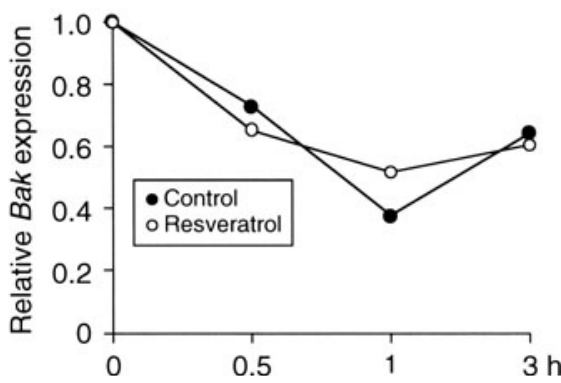

(Fig. 4c), while it had no effect on expression of mRNAs for Bcl-2 (Fig. 4b), Bad (Fig. 4d), Bax (Fig. 4e), and Bak (Fig. 4f). Collectively, resveratrol may disrupt mitochondrial membrane potentials by reducing $\mathrm{Bcl}-\mathrm{X}_{\mathrm{L}}$ expression through a pathway relevant to sirtuin 1-mediated transcription.

Resveratrol activates caspase- 3 and caspase- 9 through mitochondrial damage in a sirtuin 1-dependent manner

Mitochondrial damage allows release of apoptosis-related factors including cytochrome c. In the Western blot analysis using the mitochondrial and cytosolic component from MH7A cells, resveratrol $(100 \mu \mathrm{M})$ increased the presence of cytosolic cytochrome $\mathrm{c}$ in parallel with a treatment time (3-24 h)-dependent decrease in the presence of mitochondrial cytochrome c (Fig. 5). This explains that resveratrol stimulates release of cytochrome $\mathrm{c}$ from the mitochondria into the cytosol.

In the enzymatic assay of caspase activity, resveratrol $(100 \mu \mathrm{M})$ significantly activated caspase-3 and caspase-9, but no activation of caspase- 8 was obtained (Fig. 6). Resveratrol-induced activation of caspase- 3 and caspase- 9 was inhibited by sirtinol $(10 \mu \mathrm{M})$ (Fig. 6). Consequently, the 


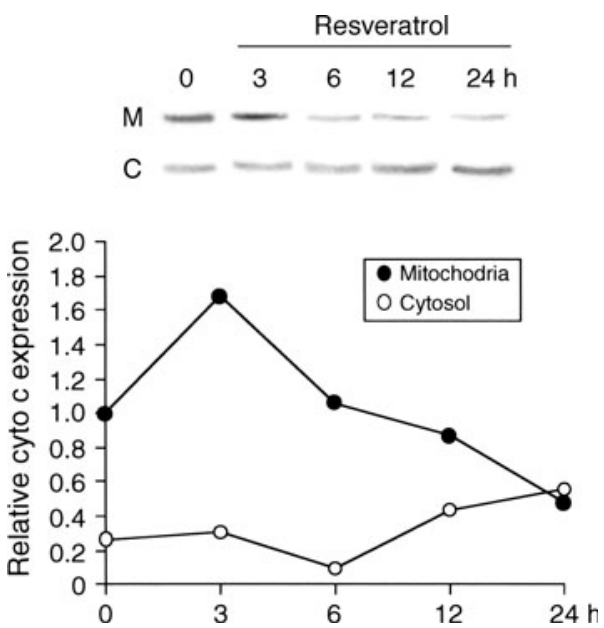

Fig. 5 Resveratrol stimulates cytochrome c release from the mitochondria. MH7A cells were treated with resveratrol $(100 \mu \mathrm{M})$ for 3-6 $\mathrm{h}$ in serum-free culture medium, followed by fractionation into the mitochondrial (M) and cytosolic component $(\mathbf{C})$, and Western blotting was carried out. In the graph, each point represents the ratio against the immunoreactive intensity at $0 \mathrm{~h}$ for the mitochondrial component regarding as 1 . cyto c, cytochrome c. Note that similar results were obtained with 3 independent experiments

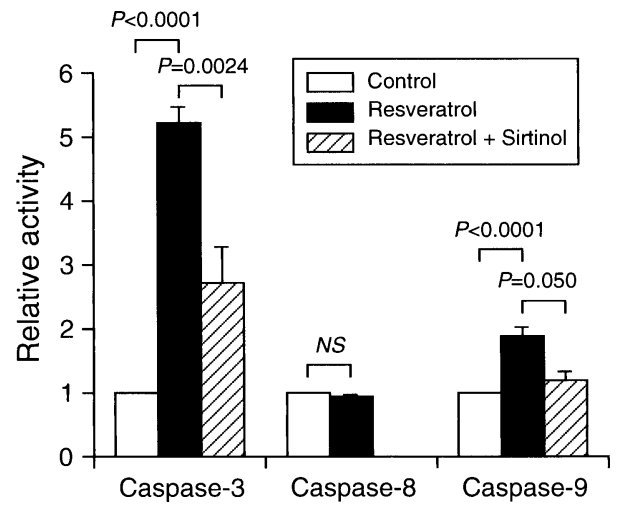

Fig. 6 Resveratrol activates caspase-3 and caspase-9 in a SIRT1dependent manner. MH7A cells were treated with resveratrol $(100 \mu \mathrm{M})$ in the absence and presence of sirtinol $(10 \mu \mathrm{M})$ for $24 \mathrm{~h}$ in serum-free culture medium, and caspase activities were assayed. In the graph, each column represents the mean $( \pm$ SEM) ratio against basal levels (caspase activities for cells untreated with any drug) $(n=4-6) . P$ values, unpaired $t$-test. $N S$ not significant

results indicate that resveratrol activates caspase- 9 and the effector caspase-3 in association with mitochondrial damage allowing cytochrome $\mathrm{c}$ release in a sirtuin-dependent manner, to induce MH7A cell apoptosis.

\section{Discussion}

In the present study, resveratrol reduced the viability of MH7A cells, a human rheumatoid arthritis synovial cell line. Resveratrol increased TUNEL-positive cells and stimulated H2A.X phosphorylation, which confirms resveratrol-induced MH7A cell apoptosis. Resveratrol disrupted mitochondrial membrane potentials in MH7A cells, stimulated cytochrome $\mathrm{c}$ release from the mitochondria into the cytosol, and activated caspase- 3 and caspase-9. For a mitochondria-mediated apoptotic pathway, damaged mitochondria releases apoptosis-related proteins such as cytochrome c, apoptosis-inducing factor (AIF), Smac/ DIABLO, Omi/HtrA2, and endonuclease $\mathrm{G}$ into the cytosol, and released cytochrome c activates caspase- 3 by forming an apoptosome complex together with apoptosis proteases activating factor-1 (Apaf-1) and caspase-9 [14]. Resveratrol, accordingly, appears to induce MH7A cell apoptosis by activating caspase- 9 and the effector caspase3 in concert with mitochondrial disruption allowing cytochrome c release from the mitochondria into the cytosol.

Amazingly, resveratrol upregulated the expression of the sirtuin 1 mRNA in MH7A cells, and resveratrol-induced MH7A cell death, mitochondrial damage, and caspase-3/-9 activation were prevented by a sirtuin 1 inhibitor. This confirms that sirtuin 1 plays a critical role in resveratrolinduced MH7A cell apoptosis. Sirtuin 1 may regulate apoptosis-related gene transcription mediated by FOXO or NF- $\kappa \mathrm{B}[16,17]$. The Bcl-2 family keeps mitochondrial integrity and controls release of mitochondrial proteins such as cytochrome $\mathrm{c}$ from the mitochondria. In the present study, resveratrol downregulated the expression of the Bcl$\mathrm{X}_{\mathrm{L}}$ mRNA in MH7A cells, although expression of mRNAs for Bcl-2, Bax, Bad, and Bak was not affected. This, taken together with the finding that resveratrol-induced MH7A cell death was attenuated by an HDAC inhibitor, raises the possibility that resveratrol perturbs mitochondrial membrane potentials by downregulating $\mathrm{Bcl}-\mathrm{X}_{\mathrm{L}}$ gene transcription in a sirtuin 1-dependent manner, followed by mitochondrial apoptotic events.

In the previous study, resveratrol-induced apoptosis in fibroblast-like synoviocytes derived from patients with rheumatoid arthritis by activating caspase- 8 as a primary target, which cleaves Bid, causing mitochondrial damage that triggers the activation of caspase- 9 and the effector caspase-3, without affecting the levels of $\mathrm{Bax}, \mathrm{Bcl}-\mathrm{X}_{\mathrm{L}}$, and Bcl-2 [15]. The resveratrol action there is completely distinct from the action found in the present study. For resveratrol-induced MH7A cell apoptosis, sirtuin 1, that downregulates expression of the $\mathrm{Bcl}-\mathrm{X}_{\mathrm{L}} \mathrm{mRNA}$, was a primary target of resveratrol, and no activation of caspase- 8 was obtained. This may represent an additional resveratrol action on apoptosis in human rheumatoid arthritis synovial cells. The reason for difference in the resveratrol actions between fibroblast-like synoviocytes and MH7A cells, however, remains to be explored.

In summary, the results of the present study show that resveratrol disrupts mitochondrial membrane potentials as 
a result of decreased Bcl- $\mathrm{X}_{\mathrm{L}}$ expression, allowing cytochrome $\mathrm{c}$ from the mitochondria into the cytosol, thereby activating caspase- 9 and the effector caspase- 3 , to induce MH7A cell apoptosis in a sirtuin 1-dependent manner. This suggests that resveratrol is capable of preventing hyperplasia of synovial cells. Resveratrol, therefore, could be developed as a promising drug for the treatment of rheumatoid arthritis.

Acknowledgments We thank Dr. Miyazawa (Kissei Pharmaceutical Co., Ltd.) for his help in dealing with MH7A cells.

Open Access This article is distributed under the terms of the Creative Commons Attribution Noncommercial License which permits any noncommercial use, distribution, and reproduction in any medium, provided the original author(s) and source are credited.

\section{References}

1. Eastgate JA, Symons JA, Wood NC, Grinlinton FM, di Giovine FS, Duff GW (1988) Correlation of plasma interleukin-1 levels with disease activity in rheumatoid arthritis. Lancet 2:706-709

2. Saxne T, Palladino MA Jr, Heinegard D, Talal N, Wollheim FA (1998) Detection of tumor necrosis factor-a but not tumor necrosis factor-b in rheumatoid arthritis synovial fluid and serum. Arthritis Rheum 31:1041-1044

3. Olsen NJ, Stein CB (2004) New drugs for rheumatoid arthritis. N Engl J Med 350:2167-2179

4. den Broeder A, van de Putte L, Rau R, Schattenkirchner M, Van Riel P, Sander O, Binder C, Fenner H, Bankmann Y, Velagapudi R, Kempeni J, Kupper H (2002) A single dose, placebo controlled study of the fully human anti-tumor necrosis factor- antibody adalimumab (D2E7) in patients with rheumatoid arthritis. J Rheumatol 9:2288-2298

5. Elliott PJ, Jirousek M (2008) Sirtuins: novel targets for metabolic disease. Curr Opin Investig Drugs 9:371-378
6. Karuppagounder SS, Pinto JT, Xu H, Chen HL, Beal MF, Gibson GE (2009) Dietary supplementation with resveratrol reduces plaque pathology in a transgenic model of Alzheimer's disease. Neurochem Int 54:111-118

7. Elmali N, Baysal O, Harma A, Esenkaya I, Mizrak B (2007) Effects of resveratrol in inflammatory arthritis. Inflammation 30:1-6

8. Molnar V, Garai J (2005) Plant-derived anti-inflammatory compounds affect MIF tautomerase activity. Int Immunopharm 5:849-856

9. Penberthy WT (2007) Pharmacological targeting of IDO-mediated tolerance for treating autoimmune disease. Curr Drug Metab $8: 245-266$

10. Yasuda Y, Saito M, Yamamura T, Yaguchi T, Nishizaki T (2009) Extracellular adenosine induces apoptosis in Caco-2 human colonic cancer cells by activating caspase-9/-3 via $\mathrm{A}_{2 \mathrm{a}}$ adenosine receptors. J Gastroenterol 44:56-65

11. Kaeberlein M, McDonagh T, Heltweg B, Hixon J, Westman EA, Caldwell SD, Napper A, Curtis R, DiStefano PS, Fields S, Bedalov A, Kennedy BK (2005) Substrate-specific activation of sirtuins by resveratrol. J Biol Chem 280:17038-17045

12. Lagouge M, Argmann C, Gerhart-Hines Z, Meziane H, Lerin C, Daussin F, Messadeq N, Milne J, Lambert P, Elliott P, Geny B, Laakso M, Puigserver P, Auwerx J (2006) Resveratrol improves mitochondrial function and protects against metabolic disease by activating SIRT1 and PGC-1 $\alpha$. Cell 127:1109-1122

13. Shakibaei M, Harikumar KB, Aggarwal BB (2009) Resveratrol addiction: to die or not to die. Mol Nutr Food Res 53:115-128

14. Wang X (2001) The expanding role of mitochondria in apoptosis. Genes Dev 15:2922-2933

15. Byun HS, Song JK, Kim YR, Piao L, Won M, Park KA, Choi BL, Lee H, Hong JH, Park J, Seok JH, Lee YJ, Kang SW, Hur GM (2008) Caspase-8 has an essential role in resveratrol-induced apoptosis of rheumatoid fibroblast-like synoviocytes. Rheumatology 47:301-308

16. Giannakou ME, Partridge L (2004) The interaction between FOXO and SIRT1: tipping the balance towards survival. Trends Cell Biol 14:408-412

17. Salminen A, Kaarniranta K (2009) Regulation of the aging process by autophagy. Trends Mol Med 15:217-224 